\title{
Publisher Correction: Universal strategy for Ohmic hole injection into organic semiconductors with high ionization energies
}

Naresh B. Kotadiya, Hao Lu, Anirban Mondal (D), Yutaka le (D), Denis Andrienko (D), Paul W. M. Blom

and Gert-Jan A. H. Wetzelaer

Correction to: Nature Materials https://doi.org/10.1038/s41563-018-0022-8, published online 19 February 2018.

In the html version of this Article originally published, Paul W. M. Blom and Gert-Jan A. H. Wetzelaer were incorrectly listed as Paul M. W. Blom and Gert-Jan H. A. Wetzelaer, respectively, due to a technical error. This has now been amended in all online versions of the Article.

Published online: 6 March 2018

https://doi.org/10.1038/s41563-018-0043-3 